\title{
Uso da técnica de swim-up para a remoção do Vírus da Artrite Encefalite Caprina do sêmen de reprodutores infectados
}

\author{
[Use of swim-up technique for removal of the Caprine Arthritis Encephalitis \\ Virus in the semen of infect bucks]
}

\author{
A.A. Ávila ${ }^{1}$, L.H. Síder ${ }^{2}$, A.K.A. Veras $^{3}$, R.R. Pinheiro ${ }^{2}$, M.L.M. Oliveira ${ }^{3}$, P.A.F. Silva ${ }^{4}$, \\ S.D. Sousa ${ }^{5}$, A. Andrioli ${ }^{2}$ \\ ${ }^{1}$ Aluna de pós-graduação - Universidade Estadual Vale do Acaraú - UVA - \\ ${ }^{2}$ Embrapa Caprinos e Ovinos - CNPC - Sobral, CE \\ ${ }^{3}$ Universidade Estadual Vale do Acaraú - UVA - Sobral, CE \\ ${ }^{4}$ Instituto Superior de Teologia Aplicada - INTA - Sobral, CE \\ ${ }^{5}$ Universidade Federal do Ceará - UFC - Fortaleza, CE
}

\begin{abstract}
RESUMO
Neste estudo, 67 ejaculados foram avaliados, antes e depois da técnica de swim-up, em relação à qualidade seminal e à presença do CAEV. Das 67 amostras testadas por PCRn, antes do swim-up, 47 (70,15\%) foram positivas para o DNA pró-viral. No entanto, quatro amostras adicionais foram positivas ao RT-nested PCR após o swim-up, o que permite dizer que, pelo menos, 76,12\% (51/67) delas estavam infectadas antes da lavagem. Todavia, em 23,88\% (16/67) das amostras não foi detectada a presença do CAEV. Após a aplicação da técnica de swim-up, constatou-se, pela PCRn e RT-nested PCR, que houve uma redução significativa $\left(\chi^{2}=\right.$ 9,078; $\mathrm{p}<0,001)$ da presença do CAEV nas amostras seminais, pois 28 de 51 amostras positivas resultaram livres do vírus $(54,90 \%)$, tanto para DNA pró-viral quanto para o vírus livre. Em relação à motilidade individual progressiva (MIP) e vigor espermático obtidos antes e depois da técnica de swim-up, observou-se uma diminuição significativa em suas médias, sendo o MIP de 86,42\% para 71,49\%, já o vigor espermático de 4,16 para 3,93. Conclui-se que a eliminação do CAEV no sêmen é de caráter intermitente, e que a associação da PCRn e RT-nested PCR é uma opção segura para a certificação sanitária individual das amostras seminais quanto à presença ou ausência do CAEV. Finalmente, a técnica de swim-up promove uma redução na infectividade de amostras de sêmen contaminadas, e, além disso, é possível promover a recuperação de espermatozoides viáveis.
\end{abstract}

Palavras-chave: lavagem seminal, caprino, CAEV, PCRn, RT-nested PCR

\begin{abstract}
In this study, 67 ejaculates were assessed before and after the swim-up technique in relation to semen quality and presence of CAEV. Of the 67 samples tested by Nested PCR, before swim-up 47 (70.15\%) were positive for viral DNA. Furthermore, four additional samples were positive for RT-nested PCR after swim-up, which allows us to affirm that at least 76.12\% (51/67) were infected before washing. However, 23.88\% (16/67) of the samples did not detect the presence of CAEV. After application of the swim-up technique it was found, by Nested PCR and RT-nested PCR, that there was a significant decrease $\left(\chi^{2}=9.078, p<0.001\right)$ in the presence of CAEV in semen samples, once 28 of 51 positive samples were free from the virus $(54.90 \%)$ for both proviral DNA and the free form of the virus. Regarding individual progressive motility (IPM) and spermatic vigor obtained before and after the swim-up technique, a significant decrease was observed in the average, being $86.42 \%$ of the IPM to $71.49 \%$ and the spermatic vigor from 4.16 for the 3.93. It is concluded that the removal of CAEV in semen has an intermittent character, and the combination of PCR and RT-nested PCR is a safe option for health certification of individual semen samples for the presence or absence of CAEV. Finally, the swim-up technique promotes a reduction in the infectivity of contaminated semen samples, and it is possible to promote the recovery of high individual progressive motility sperm and sperm vigor.
\end{abstract}

Keywords: seminal washing, goat, CAEV, Nested PCR, RT-nested PCR

Recebido em 26 de julho de 2013

Aceito em 21 de agosto de 2014

E-mail: amandazootec@yahoo.com.br 


\section{INTRODUÇÃO}

A inseminação artificial (IA) torna possível o intercâmbio de sêmen no âmbito nacional e internacional, o que acelera os programas de melhoramento genético. No entanto, a IA também tem alto potencial de disseminação de patógenos que podem ser encontrados no sêmen em associação com células sanguíneas infectadas, aderidos à superfície dos espermatozoides ou mesmo livres no plasma seminal (Hare, 1985).

A Artrite Encefalite Caprina (CAE) é uma enfermidade infectocontagiosa crônica, que tem como agente etiológico um vírus pertencente à família Retroviridae, subfamília Lentivirínae e ao gênero Lentivírus, que está presente no sêmen de animais infectados (Andrioli et al., 2006), e o sistema reprodutor feminino é porta de entrada desse vírus (Souza et al., 2013).

De acordo com Piccolomini (2010), diversas técnicas de lavagem do sêmen, como o gradiente descontínuo de Percoll@ e o swim-up foram desenvolvidas com o intuito de separar os espermatozoides de alta mobilidade para uso em biotécnicas reprodutivas, além de reduzir contaminantes microbianos associados ao sêmen. Entretanto, esses procedimentos de lavagem podem reduzir a viabilidade espermática (Drobnis et al., 1991).

O uso de procedimentos de lavagem de sêmen associados a teste de biologia molecular de alta sensibilidade, como a Reação em Cadeia de Polimerase nested (PCRn) e a PCRn, precedida pela transcrição reversa (RT-PCR $n$ ) para diagnóstico do vírus da Artrite Encefalite Caprina (CAEV) nesse material, pode apresentar um impacto significativo na prevenção da transmissão da CAE pela via reprodutiva. As técnicas moleculares de $\mathrm{PCR} n$ e a RT-nested PCR detectam, respectivamente, o DNA próviral e RNA genômico livre do CAEV, e podem ser utilizadas para o diagnóstico precoce do vírus (Sider et al., 2010).

A técnica de lavagem de sêmen por swim-up é simples e de baixo custo (Jameel, 2008); no entanto, pouco se sabe sobre a eficácia dessa técnica na remoção do CAEV. Dessa forma, no presente estudo visou-se determinar a influência da técnica de swim-up sobre a viabilidade espermática e sua eficiência na remoção do CAEV de amostras de sêmen oriundas de reprodutores infectados.

\section{MATERIAL E MÉTODOS}

O experimento foi conduzido nas dependências da Embrapa Caprinos e Ovinos, situada em Sobral, Ceará (latitude $3^{\circ} 45^{\prime} 0,5^{\prime}$ ' sul, longitude $40^{\circ} 20^{\prime} 45,8^{\prime}$ ' oeste, 11 metros de altitude), nos meses de março a dezembro de 2012.

Para tanto, foram selecionados cinco reprodutores caprinos, naturalmente infectados pelo CAEV, das raças Moxotó, Canindé e Anglo Nubiano, com idade entre dois a seis anos, que foram doadores de 67 ejaculados. Para comprovação da infecção pelo CAEV dos machos, foi coletado sangue e realizado o diagnóstico por Western Blot (WB), segundo metodologia de Rodrigues et al. (2009) adaptada de Pinheiro (2001).

As coletas de sêmen foram semanais e utilizouse o método da vagina artificial (Mies Filho, 1962), tendo como manequim uma fêmea ovarectomizada, com estro induzido pela aplicação de 1,0mg de benzoato de estradiol.

Imediatamente após a coleta, o sêmen era encaminhado para o laboratório de biotecnologia de sêmen, mantido em banho-maria a $37^{\circ} \mathrm{C}$ e registrados o volume, a concentração espermática, a motilidade individual progressiva (MIP) e o vigor espermático, conforme manual do Colégio Brasileiro de Reprodução Animal CBRA (Colégio..., 1997).

Foi retirada uma alíquota de $100 \mu \mathrm{L}$ de cada sêmen coletado para a realização da $\mathrm{PCR} n$, antes de ser submetido à técnica swim-up, para verificar a presença ou ausência do DNA próviral do CAEV.

Antes da PCRn, as alíquotas de sêmen foram previamente filtradas em coluna de Sephacryl S400 segundo técnica de Santurde et al. (1996), para retirada das impurezas. Após a filtragem, $3 \mu \mathrm{L}$ das amostras foram transferidas para um tubo tipo eppendorf® e adicionado $200 \mu \mathrm{L}$ de solução de Chelex 100 a $5 \%, 2 \mu \mathrm{L}$ de proteinase $\mathrm{K}(10 \mu \mathrm{g} / \mu \mathrm{L})$ e $7 \mu \mathrm{L}$ de Dithiothreitol a $1 \mathrm{M}$, sendo então incubadas em banho-maria, a $56^{\circ} \mathrm{C}$, por 60 minutos. Logo após as amostras foram 
submetidas ao vortex por 10 segundos, seguindose banho de água fervente por 8 minutos, para inativação da proteinase $K$. Por fim foram centrifugadas por três minutos a $13.000 \mathrm{xg}$ e acondicionadas em freezer, $-20^{\circ} \mathrm{C}$, até sua utilização.

Para a amplificação por Nested PCR, do DNA, foram utilizados dois pares de iniciadores derivados de sequências das regiões gag da amostra padrão CAEV-Cork (Saltarelli et al., 1990), sendo os iniciadores externos P1 (5'CAAGC AGCAGGAGGGAGAAGCTG-3', nucleotídeos 953 a 975) e P2 (5'TCCTACCCCC ATAATTTGATCCAC-3', nucleotídeos 1249 a 1226), descritos por Barlough et al. (1994), resultando na amplificação de um fragmento de DNA de $297 \mathrm{pb}$. O produto dessa amplificação foi então submetido a uma segunda rodada de amplificação com os iniciadores internos direcionados para o mesmo gene, P3 (5'GTTCCAGCAACTGCAAACAGTAGCAAT G-3', nucleotídeos 997 a1024) e P4 (5'ACCTTTCTGCTTCTTCATTTAATTTCCC-

3', nucleotídeos 1181 a 1154), resultando em um fragmento final de $187 \mathrm{pb}$ (Rimstad et al., 1993).

As reações de amplificação foram realizadas em termociclador, constituindo-se de um passo inicial para desnaturar as fitas de DNA, de $94^{\circ} \mathrm{C}$ por 5 minutos; seguido de 35 ciclos: $94^{\circ} \mathrm{C}-1$ minuto, $56^{\circ} \mathrm{C}-1$ minuto, $72^{\circ} \mathrm{C}-45$ segundos; e extensão final a $72^{\circ} \mathrm{C}$ por 7 minutos; $4^{\circ} \mathrm{C}$ - até a coleta da amostra.

As amostras amplificadas e os controles positivos e negativos, juntamente com o marcador de peso molecular (DNA ladder), foram submetidos à eletroforese em gel de agarose $1 \%$ em TBE (Tris, borato e EDTA 0,5X) corado com brometo de etídio adicionado ao gel $(0,5 \mu \mathrm{g} / \mathrm{mL})$. Cada amostra $(10 \mu \mathrm{L})$, juntamente com $2 \mu \mathrm{L}$ de tampão de corrida, foi submetida à eletroforese em cuba horizontal, com TBE $(0,5 \mathrm{X})$, por 40 minutos (2A e 90 volts). A visualização das bandas de DNA foi realizada em transiluminador de luz ultravioleta e registrada fotograficamente.

Para realização da técnica de swim-up, $100 \mu \mathrm{L}$ de sêmen fresco foram colocados ao fundo de um tubo falcon ${ }^{\circledR}$ de $15 \mathrm{~mL}$, seguido da deposição lenta pela parede do tubo de $2 \mathrm{~mL}$ de meio de cultura para gametas, Sp-TALP, e mantidos com inclinação de $45^{\circ}$ à temperatura de $37^{\circ} \mathrm{C}$, em estufa de $\mathrm{CO}_{2}$ a $5 \%$ por 60 minutos.

Após o tempo de incubação, $600 \mu \mathrm{L}$ do sobrenadante de cada amostra contendo os espermatozoides foram retirados e divididos igualmente em dois eppendorfs para serem submetidos à PCRn e a RT-nested PCR. Em seguida, esses foram centrifugados a $200 \mathrm{xg}$ por 10 minutos à temperatura de $37^{\circ} \mathrm{C}$.

Após a centrifugação, o sobrenadante foi descartado e o pélete espermático, formado após centrifugação, ressuspendido em $200 \mu \mathrm{L}$ de nova solução de sp-TALP, que também era mantida à temperatura de $37^{\circ} \mathrm{C}$ para evitar a morte dos espermatozoides por choque térmico. Em seguida, uma gota da amostra, contendo os espermatozoides, foi submetida à avaliação da MIP e vigor espermático (Colégio..., 1997).

Os eppendorfs contendo as amostras seminais de cada animal, após o swim-up, foram submetidos à extração de DNA e de RNA, sendo que, antes da extração propriamente dita, foi removido o meio de cultura através de duas centrifugações a $13.000 \mathrm{xg}\left(4^{\circ} \mathrm{C}\right.$, por 10 minutos $)$ e ressuspensão dos péletes espermáticos em $200 \mu \mathrm{L}$ de PBS $1 \mathrm{X}$ estéril.

Para a extração de DNA, o procedimento transcorreu conforme metodologia descrita anteriormente. Já para a extração de RNA, foi utilizado o protocolo do fabricante do kit baseado em coluna de sílica (NucleoSpin® RNA II Marcherey-Nagel), o qual foi adaptado ao procedimento de extração de RNA das amostras de sêmen e aplicado àquelas oriundas do procedimento de swim-up (Sider et al., 2010). A partir do RNA extraído, foi sintetizado o DNA complementar (cDNA) com o kit Improm II ${ }^{\mathrm{TM}}$ Reverse Transcription System (Promega), segundo as instruções do fabricante.

As amostras oriundas do processamento de extração de DNA e RNA foram submetidas à reação de amplificação por $\mathrm{PCR} n$ e visualizadas as bandas de DNA por eletroforese, conforme descrito anteriormente.

Para comparação dos resultados obtidos para os valores de MIP e vigor espermático antes e depois da técnica de swim-up, os dados foram submetidos ao teste de Wilcoxon, a fim de 
verificar se houve ou não alteração dos parâmetros espermáticos, considerando-se o nível de significância de 5\%. O software estatístico utilizado para as análises foi o SAS 9.2. Para comparar os dados referentes à presença ou ausência do vírus antes e depois da técnica de swim-up, foi utilizado o teste de Fisher com o nível de significância adotado de $5 \%$.

\section{RESULTADOS E DISCUSSÃO}

Das 67 amostras avaliadas por PCR $n$ antes do swim-up (Tab. 1), 47 (70,15\%) foram positivas para a presença do DNA pró-viral. Além disso, observou-se que quatro amostras adicionais, negativas ao PCR $n$ pré swim-up, foram positivas ao RT-nested PCR após o swim-up, o que permite dizer que no mínimo 76,12\% (51/67) das amostras de sêmen coletadas estavam infectadas pelo CAEV. Esses resultados estão acima dos relatados por Andrioli et al. (2006) e Paula et al. (2009), que também detectaram a presença de partículas virais no sêmen in natura de reprodutores caprinos infectados pelo $\mathrm{CAEV}$, em $35,7 \%$ e $10,98 \%$ das amostras, respectivamente.

Em 23,88\% (16/67) das amostras de sêmen, não foi detectada a presença do material genético do CAEV, embora os animais fossem portadores do vírus, o que indica que a frequência de eliminação de células infectadas no sêmen pode ter caráter intermitente, uma vez que todos os animais apresentaram, durante o experimento, amostras negativas e positivas à $\mathrm{PCR} n$, o que também foi observado por outros autores (Andrioli et al., 2006; Paula et al., 2009; Cruz, 2009), todavia não se descarta a possibilidade da presença do vírus em sua forma livre, uma vez que a técnica utilizada pré swim-up, PCRn, detectava apenas a presença de DNA pró-viral.

Segundo Andrioli et al. (2006), a frequência de aparecimento do CAEV no sêmen pode ser mais elevada em animais que sofreram algum trauma testicular, o que desencadearia, consequentemente, um maior fluxo de células inflamatórias do sistema monocítico-fagocitário para o trato genital. Além disso, Peterson et al. (2008) constataram a presença de DNA pró-viral em amostras teciduais oriundas dos testículos, epidídimo e glândulas sexuais acessórias, indicando que vários órgãos sexuais masculinos podem contribuir diretamente para o derramamento do CAEV no ejaculado caprino.
Outro fator que pode ter contribuído para o grande número de amostras infectadas seria o estresse térmico durante a estação reprodutiva, pois o período do experimento, segundo o Instituto Nacional de Meteorologia (Instituto..., 2012), correspondeu a um período de pouca precipitação pluviométrica, média de $37,44 \mathrm{~mL}$ no ano, e com altas temperaturas, média de $35,6^{\circ} \mathrm{C}$ no ano, indicando que os animais podem ter sofrido estresse térmico. De acordo com Peterson et al. (2008) e Paula et al. (2009), o estresse pode reativar a multiplicação viral e subsequente excreção.

A associação de duas técnicas moleculares, Nested PCR e RT-nested PCR, possibilitou constatar que, após a aplicação da técnica de swim-up, houve uma redução significativa $\left(\chi^{2}=\right.$ 9,078; $\mathrm{p}<0,001)$ da presença do CAEV nas amostras seminais, em que 28 de 51 (54,90\%) amostras anteriormente positivas resultaram livres do vírus. Porém, esses achados foram inferiores aos encontrados por Ricarte et al. (2010), que não detectaram, por meio de imunohistoquímica, amostras de sêmen positivas para o CAEV após teste de swim-up de animais naturalmente infectados. Contudo, no mesmo trabalho, os autores observaram uma amostra positiva após o swim-up de animais experimentalmente infectados pelo CAEV. Os resultados encontrados pelos autores podem ter sido influenciados pelo baixo número de amostras positivas, para o CAEV, antes de terem sido submetidas à técnica de swim-up.

Embora os programas voltados para a área de reprodução humana tenham obtido sucesso nos protocolos de lavagem para remoção do vírus do HIV (Queiroz et al., 2008), em caprinos esses procedimentos ainda precisam ser otimizados. Andrioli et al. (2006), ao compararem amostras de sêmen antes e após procedimento de lavagem seminal, observaram que $35,7 \%$ das amostras não lavadas eram positivas e após lavagem constataram que houve diminuição, não significativa, das amostras positivas para $7,1 \%$. Os mesmos autores observaram que, após causar injúria testicular, a porcentagem de amostras positivas submetidas à lavagem seminal diminuiu significativamente, de $71,4 \%$ para $28,6 \%$. 
Ávila et al.

Tabela 1. Resultados do diagnóstico por Nested PCR e RT-nested PCR em amostras de sêmen de reprodutores caprinos soropositivos para o CAEV

\begin{tabular}{|c|c|c|c|}
\hline \multirow{2}{*}{$\begin{array}{l}\text { Animal / } \\
\text { amostra }\end{array}$} & \multicolumn{3}{|c|}{ Detecção do CAEV em amostras de sêmen $(n=67)$ de reprodutores positivos por WB } \\
\hline & PCRn antes do swim-up & PCRn após swim-up & RT-nested PCR após swim-up \\
\hline $1 / 1$ & Positivo & positivo & Positivo \\
\hline $1 / 2$ & Negativo & negativo & Negativo \\
\hline $1 / 3$ & Negativo & negativo & Negativo \\
\hline $1 / 4$ & Positivo & negativo & Negativo \\
\hline $1 / 5$ & Negativo & negativo & Negativo \\
\hline $1 / 6$ & Positivo & negativo & Negativo \\
\hline $1 / 7$ & Negativo & negativo & Negativo \\
\hline $1 / 8$ & Positivo & negativo & Negativo \\
\hline $1 / 9$ & Positivo & positivo & Negativo \\
\hline $1 / 10$ & Negativo & negativo & Negativo \\
\hline $1 / 11$ & Positivo & positivo & Negativo \\
\hline $1 / 12$ & Negativo & negativo & Positivo \\
\hline $2 / 1$ & Positivo & positivo & Negativo \\
\hline $2 / 2$ & Positivo & negativo & Positivo \\
\hline $2 / 3$ & Negativo & negativo & Positivo \\
\hline $2 / 4$ & Positivo & positivo & Negativo \\
\hline $2 / 5$ & Positivo & negativo & Negativo \\
\hline $2 / 6$ & Positivo & negativo & Negativo \\
\hline $2 / 7$ & Negativo & negativo & Negativo \\
\hline $2 / 8$ & Positivo & negativo & Negativo \\
\hline $2 / 9$ & Negativo & negativo & Negativo \\
\hline $2 / 10$ & Positivo & negativo & Negativo \\
\hline $2 / 11$ & Positivo & negativo & Negativo \\
\hline $2 / 12$ & Positivo & positivo & Negativo \\
\hline $2 / 13$ & Positivo & negativo & Negativo \\
\hline $2 / 14$ & Positivo & positivo & Negativo \\
\hline $3 / 1$ & Positivo & positivo & Negativo \\
\hline $3 / 2$ & Negativo & negativo & Negativo \\
\hline $3 / 3$ & Positivo & positivo & Negativo \\
\hline $3 / 4$ & Positivo & negativo & Negativo \\
\hline $3 / 5$ & Positivo & negativo & Negativo \\
\hline $3 / 6$ & Negativo & negativo & Negativo \\
\hline $3 / 7$ & Negativo & negativo & Negativo \\
\hline $3 / 8$ & Positivo & negativo & Negativo \\
\hline $3 / 9$ & Positivo & negativo & Negativo \\
\hline $3 / 10$ & Positivo & negativo & Negativo \\
\hline $3 / 11$ & Positivo & positivo & Negativo \\
\hline $3 / 12$ & Positivo & negativo & Negativo \\
\hline $3 / 13$ & Positivo & positivo & Negativo \\
\hline $3 / 14$ & Positivo & negativo & Negativo \\
\hline $4 / 1$ & Positivo & positivo & Negativo \\
\hline $4 / 2$ & Negativo & negativo & Positivo \\
\hline $4 / 3$ & Positivo & negativo & Negativo \\
\hline $4 / 4$ & Positivo & negativo & Negativo \\
\hline $4 / 5$ & Negativo & negativo & Positivo \\
\hline $4 / 6$ & Positivo & negativo & Negativo \\
\hline $4 / 7$ & Positivo & negativo & Negativo \\
\hline $4 / 8$ & Positivo & negativo & Negativo \\
\hline $4 / 9$ & Positivo & negativo & Positivo \\
\hline
\end{tabular}




\begin{tabular}{cccc}
\hline Animal / & \multicolumn{2}{c}{ Detecção do CAEV em amostras de sêmen $(\mathrm{n}=67)$ de reprodutores positivos por WB } \\
\cline { 2 - 4 } amostra & PCRn antes do swim-up & PCRn após swim-up & RT-nested PCR após swim-up \\
\hline 4 / 10 & Positivo & negativo & Negativo \\
4 / 11 & Positivo & negativo & Negativo \\
4 / 12 & Positivo & positivo & Negativo \\
4 / 13 & Positivo & positivo & Negativo \\
$4 / 14$ & Positivo & positivo & Positivo \\
\hline $5 / 1$ & Negativo & negativo & Negativo \\
$5 / 2$ & Positivo & negativo & Negativo \\
$5 / 3$ & Positivo & positivo & Negativo \\
$5 / 4$ & Positivo & positivo & Positivo \\
$5 / 5$ & Positivo & negativo & Negativo \\
$5 / 6$ & Negativo & negativo & Negativo \\
$5 / 7$ & Positivo & negativo & Negativo \\
$5 / 8$ & Negativo & negativo & Negativo \\
$5 / 9$ & Negativo & negativo & Negativo \\
$5 / 10$ & Negativo & negativo & Negativo \\
$5 / 11$ & Positivo & negativo & Negativo \\
$5 / 12$ & Negativo & negativo & Negativo \\
$5 / 13$ & Positivo & negativo & Negativo \\
\hline
\end{tabular}

Quando avaliada individualmente, o resultado da $\mathrm{PCR} n$ demonstrou que o procedimento de swimup conseguiu remover, significativamente $\left(\chi^{2}=\right.$ $0,1965 ; \mathrm{p}<0,002)$, grande parte das células infectadas, uma vez que 30 amostras, de um total de $47(63,83 \%)$ positivas para a presença de DNA pró-viral, obtiveram resultado negativo após lavagem espermática. O grande número de amostras negativas provavelmente está relacionado com a concentração das células não espermáticas, infectadas pelo CAEV, que permaneceram ao fundo do tubo em que foram incubadas. Segundo Jameel (2008), o procedimento de swim-up é baseado no movimento dos espermatozoides que migram para um meio de cultura sobreposto ao sêmen, deixando para trás espermatozoides imaturos, aqueles sem velocidade de progressão direcional, além de células não reprodutivas e redução de agentes microbianos.

Hanabusa et al. (2000), ao avaliarem duas etapas do procedimento de lavagem espermática, centrifugação em gradiente de Percoll e swim-up, visando à eliminação do RNA e DNA pró-viral do HIV, observaram que a centrifugação em gradiente de Percoll deixou detectáveis a presença de RNA e DNA pró-viral do HIV em uma das 12 amostras (8\%) de pacientes com infecção. Já após a utilização do procedimento de migração ascendente, esses foram diminuídos para níveis não detectáveis. Portanto, o swim-up serve como complemento para eliminação do vírus existente nas amostras de sêmen.

Já avaliando os resultados da RT-nested PCR, foi possível constatar que nove amostras ainda continham o vírus em sua forma livre, sendo que quatro destas eram negativas quanto à presença de DNA pró-viral antes do swim-up. Esses resultados sugerem que amostras seminais negativas para a presença de células infectadas podem não estar livres da presença do vírus. Portanto, caracterizam um risco na disseminação da enfermidade se utilizadas. Dessa forma, conclui-se que o procedimento de lavagem não foi suficiente para promover a desinfecção completa das amostras.

Estudos realizados com homens portadores do vírus HIV têm demonstrado que a retirada do plasma seminal por gradiente de densidade, antes do swim-up, possibilita a eliminação de partículas virais do sêmen, porém não separa os espermatozoides dos outros tipos celulares (Oliveira et al., 2012). Além disso, a associação de pelo menos duas técnicas de processamento seminal e o uso de terapia antirretroviral potente apresentam excelentes resultados na eliminação das fontes ativas de transmissão do vírus e obtenção de gametas seguros (Queiroz et al., 2008). Essas informações estão de acordo com Canto et al. (2006), que não detectaram o RNA do HIV em nenhuma das frações seminais analisadas após a associação das mesmas 
técnicas descritas anteriormente para o processamento seminal.

O fato de a técnica de swim-up não ter alcançado $100 \%$ de desinfecção almejada se deve provavelmente à utilização de apenas uma técnica de processamento seminal, além da falta de tratamento dos reprodutores com drogas antivirais para reduzir a carga viral. Todavia, devido ao risco comprovado de infecção por inseminação artificial (Souza et al., 2013), faz-se necessário um controle rigoroso nas centrais de comercialização de germoplasma, por meio da utilização de testes moleculares de alta sensibilidade.

Em relação à média dos parâmetros espermáticos verificados pré swim-up, tais como volume seminal $(0,89 \mathrm{~mL})$, concentração espermática $\left(3,97 \times 10^{9} \quad\right.$ sptz/mL), MIP $(86,42 \%)$ e vigor $(4,16)$, foram considerados normais e de boa qualidade para a espécie caprina (Colégio..., 1997). Essas informações corroboram os achados de Rodriguéz et al. (2005), em que foi observado que reprodutores caprinos portadores do CAEV não tiveram sua qualidade seminal afetada pela enfermidade.

De acordo com Siqueira et al. (2007), a motilidade espermática e a velocidade com que se deslocam são fundamentais para que os espermatozoides alcancem o ambiente uterino e o local de fertilização. Além disso, são os critérios mais usados na avaliação de sêmen antes e depois do processamento em laboratório.

A análise das respostas obtidas, antes e depois da técnica de swim-up, sobre a MIP e o vigor espermático no sêmen caprino (Tab. 2), revelou que houve uma diminuição significativa na média das variáveis estudadas, MIP e vigor. Esses resultados foram semelhantes aos relatados por Jameel (2008), que obteve valores médios, após swim-up, para a MIP, de $72 \%$ e vigor, de 3,7. Entretanto, valores superiores foram encontrados por $\mathrm{Ng}$ et al. (1992), que obtiveram uma recuperação de espermatozoides com motilidade média $89 \%$.

Tabela 2. Movimento individual progressivo (MIP) e vigor de espermatozoides caprinos antes e depois da técnica de swim-up

\begin{tabular}{lcc|c}
\hline \multirow{2}{*}{ Características seminais } & \multicolumn{3}{c}{ Amostras seminais analisadas (n=67) } \\
\cline { 2 - 4 } & $\begin{array}{c}\text { Antes da técnica de } \\
\text { swim- } u p\end{array}$ & $\begin{array}{c}\text { Após a técnica de swim- } \\
\text { up }\end{array}$ & $\begin{array}{c}\text { Valor da diferença } \\
\text { obtida }\end{array}$ \\
\hline MIP \% (0-100) & 86,42 & $71,49 * *$ & -14.93 \\
Vigor (0-5) & 4,16 & $3,93^{*}$ & $-0,24$ \\
\hline
\end{tabular}

*Valores marcados com apenas um asterisco diferem-se estatisticamente $(\mathrm{P}<0,05)$, antes e depois da técnica de swimup, pelo teste de Wilcoxon.

**Valores marcados com dois asteriscos diferem-se estatisticamente $(\mathrm{P}<0,001)$, antes e depois da técnica de swim-up, pelo teste de Wilcoxon.

A diminuição observada para esses parâmetros, provavelmente, estaria relacionada com o procedimento de centrifugação a que as amostras foram submetidas. Além disso, segundo Correa et al., (1997), o estresse relacionado ao tempo necessário para recuperação dos espermatozoides também pode contribuir para a elevada taxa de mortalidade e perda de capacitação dos mesmos.

Apesar da diminuição significativa encontrada neste estudo, os valores obtidos ainda são satisfatórios e compatíveis para utilização em inseminação intrauterina e fertilização in vitro, demonstrando que o método swim-up permite a recuperação de espermatozoides viáveis. Além disso, diversos autores relatam que a técnica de swim-up promove a recuperação e seleção dos melhores espermatozoides, já que apenas os mais capacitados se movimentam para a parte superior do tubo (Ng et al., 1992; Jameel, 2008).

\section{CONCLUSÕES}

Com base nos resultados obtidos, pode-se concluir que a eliminação do CAEV no sêmen possui caráter intermitente e que a associação da PCR $n$ e da RT-nested PCR é uma opção mais segura para a certificação sanitária das partidas seminais quanto à presença ou ausência do CAEV, pois amostras negativas quanto à presença de DNA pró-viral podem conter o vírus em sua forma livre, RNA viral. Além disso, a técnica de swim-up reduz o risco de veiculação do CAEV no sêmen de reprodutores infectados e possibilita a obtenção de espermatozoides viáveis. 


\section{REFERÊNCIAS}

ANDRIOLI, A.; GOUVEIA, A.M.G.; MARTINS, A.S. et al. Fatores de risco na transmissão do lentivírus caprino pelo sêmen. Pesq. Agropec. Bras., v.41, p.1313-1319, 2006.

BARLOUGH, J.; EAST, N.; ROWE, J.D. Double-nested polymerase chain reaction for detection of caprine arthritis-encephalitis virus proviral DNA in blood, milk and tissues of infected goats. J. Virol.Methods, v.50, p.101114, 1994.

COLÉGIO Brasileiro De Reprodução Animal CBRA. Manual para exame andrológico $e$ avaliação de sêmen animal. 2.ed. Belo Horizonte, MG, 1997. 35p.

CANTO, C.L.M.; SEGURADO, A.C.; PANNUTI, C. et al. Detection of HIV and HCV RNA in semen from Brazilian coinfected men using multiplex PCR before and after semen washing. Rev. Inst. Med. Trop. S. Paulo., v.48, p.201-206, 2006.

CORREA, J.R.; PACE, M.M.; ZAVOS, P.M. Relationships among frozen-thawed sperm characteristics assessed via the routine semen analysis, sperm functional tests and fertility of bulls in an artificial insemination program. Theriogenology, v.48, p.721-731, 1997.

CRUZ, J.C.M. Monitoramento sorológico e da presença do DNA pró-viral do lentivírus caprino (CAEV) no sangue e sêmen de reprodutores infectados. 2009. 35f. Tese (Doutorado em Ciência Animal) - Universidade Federal de Minas Gerais, Belo Horizonte.

DROBNIS, E.; ZHONG, C.; OVERSTREET, J. Separation of cryopreserved human sperm using Sephadex columns, washing, or Percoll gradients. J. Androl., v.12, p.201-208, 1991.

HANABUSA, H.; KUJI, N.; KATO, S. et al. An evaluation of semen processing methods for eliminating HIV-1. AIDS, v.14, p.1611-1616, 2000 .

HARE, W.C.D. Diseases transmissible by semen and embryo transfer techniques. OIE Technical Bul., v.4, p.1-117, 1985.

INSTITUTO Nacional De Meteorologia INMET. Monitoramento climático. 2012. Disponível em:<www.inmet.gov.br/portal/index. php?r=bdmep>. Acessado em: 27 mar. 2012.
JAMEEL, T. Sperm swim-up: a simple and effective technique of semen processing for intrauterine insemination. J. Pak. Med. Associ., v.58, p.71-74, 2008.

MIES FILHO, A. Novo modelo de vagina artificial para ovinos. Rev. Facul. Agro. Rio Grande do Sul, v.5, p.187-193, 1962.

NG, F.L.; LIU, D.Y.; BAKER, H.W. Comparison of Percoll, mini-Percoll and swimup methods for sperm preparation from abnormal semen samples. Hum. Reprod., v.7, p.261-266, 1992.

OLIVEIRA, M.R.A.; PATRÍCIO, D.O.; SILVA, A.B.C.; SANTOS, KJ.M. Utilização das Técnicas de Reprodução Assistida em Casais Sorodiscordantes para a Obtenção de Gametas Seguros. NewsLab, v.114, p.130-138, 2012.

PAULA, N.R.O.; ANDRIOLI, A.; CARDOSO, J.F.S. et al. Profile of the Caprine arthritisencephalitis virus (CAEV) in blood, semen from bucks naturally and experimentally infected in the semi-arid region of Brazil. Small Rum. Res., v.85, p.27-33, 2009.

PETERSON, K.; BRINKHOF, J.; HOUWERS, D. et al. Presence of pro-lentiviral DNA in male sexual organs and ejaculates of small ruminants. Theriogenology, v.69, p.433-442, 2008.

PICCOLOMINI, M.M. Alterações na Morfologia e na Viabilidade no Desenvolvimento de Embriões Bovinos Fecundados in vitro com Sêmen Exposto Experimentalmente à Escherichia coli Produtora da Toxina Shiga Stx2 (STEC). 2010. 57f. Dissertação (Mestrado em Sanidade, Segurança Alimentar e Ambiental no Agronegócio) - Instituto biológico - Agência Paulista de Tecnologia dos Agronegócios, São Paulo, 2010.

PINHEIRO, R.R. Vírus da Artrite-Encefalite Caprina: Desenvolvimento e padronização de ensaios imunoenzimáticos (ELISA e Dot-blot) $e$ estudo epidemiológico no Estado do Ceará. 2001. 115f. Tese (Doutorado em Ciência Animal) - Universidade Federal de Minas Gerais, Belo Horizonte, 2001.

QUEIROZ, P.; TANIL, C.T.; MADASCHI, C. $e t$ al. Obtenção de gametas seguros por meio de associação de técnicas de processamento seminal para casais sorodiscordantes para HIV. Rev. Bras. Ginecol. Obst., v.30, p.171-176, 2008. 
RICARTE, A.R.F.; ANDRIOLI, A.; PINHEIRO, R.R. et al. Avaliação imunohistoquímica e ultraestrutural de gametas e embriões caprinos infectados com o CAEV. Arq. Inst. Biol., v.77, p.217-223, 2010.

RIMSTAD, E.; EAST, N.E.; TORTEN, M. Delayed seroconversion following naturally acquired caprine arthritis-encephalitis virus using recombinant gag proteins. Am. J. Vet. Res., v.54, p.1858-1862, 1993.

RODRIGUEZ, H.A.M.; ÁLVAREZ, H.R.; PÉREZ, J.T. et al. Efecto del virus de artritis encefalitis caprina en el aparato reproductor de machos caprinos. Vet. Mex., v.36, p.159-176, 2005.

RODRIGUES, A.S.; SANTOS, V.W.S.; BRITO, R.L.L. et al. Comparação de dois testes sorológicos na evolução natural de caprinos leiteiros com o vírus da Artrite-Encefalite Caprina - dados preliminares. In: SINCORTE, 4. , 2009, João Pessoa. Anais... Paraíba: Sociedade Brasileira de Zootecnia. (CD-ROM).

SALTARELLI, M.; QUERAT, G.; KONINGS, D.A.M. Nucleotide sequence and transcription analysis of molecular cones of CAEV which generate infectious virus. Virology, v.179, p.347364, 1990.
SANTURDE, G.; DA SILVA, N.; VILLARES, R. et al. Rapid and high sensitivity test for direct detection of bovine herpesvirus-1 genome in clinical samples. Vet. Microbiol., v.49, p.81-92, 1996.

SIDER, L.H.; OLIVEIRA, A.N.; VERAS, A.K.A. et al. Processamento de sêmen para extração de RNA genômico do vírus da artriteencefalite caprina e diagnóstico molecular por RT-nested PCR. Sobral: Embrapa Caprinos e Ovinos, 2010, 4p. (Embrapa Caprinos e Ovinos. Comunicado técnico, 113).

SIQUEIRA, J.B.; GUIMARÃES, J.D.; COSTA, E.P. et al. Relação da taxa de gestação com sêmen bovino congelado e testes de avaliação espermática in vitro. Rev. Bras. Zootec., v.36, p.387-395, 2007.

SOUZA, K.C.; PINHEIRO, R.R.; SANTOS, D.O. et al. Transmission of the caprine arthritisencephalitis virus through artificial insemination. Smal Rum. Res., v.109, p.193-198, 2013. 